\title{
ADORNO Y REPRESENTACIÓN: ESCENARIOS COTIDIANOS DE VIDA A FINALES DEL SIGLO XVIII EN MADRID*
}

\section{Ornament and representation: everyday life stages in late 18th century Madrid}

\author{
Álvaro MOLINA \\ Universidad Nacional de Educación a Distancia \\ a.molina@geo.uned.es \\ Jesusa VEGA \\ Universidad Autónoma de Madrid \\ jesusa.vega@uam.es \\ Fecha de recepción: 10/12/2017 \\ Fecha de aceptación definitiva: 25/06/2018
}

RESUMEN: La decoración de la vivienda a finales del siglo XVIII experimentó un cambio sustancial como consecuencia de los hábitos y prácticas de la sociabilidad urbana. La nueva dimensión que cobró el hogar como ambiente de representación, bajo los dictados del "buen gusto" y la moda, hizo más necesario que nunca estar al día de las novedades. La prensa jugó un papel importante en la difusión de las modas y es determinante para recuperar esos contextos desaparecidos. A través del Diario de Madrid se puede conocer y comprender la importancia que tuvo adornar la casa entre las gentes que deseaban ser partícipes de la vida moderna, propiciando

* Esta investigación se ha desarrollado en el marco de los proyectos $\mathrm{I}+\mathrm{D}$ «El dibujante ingeniero al servicio de la monarquía hispánica. Siglos XVI-XVIII. Ciudad e ingeniería en el Mediterráneo", ref. HAR2016-78098-P (AEI/FEDER, UE), financiado por la Agencia Estatal de Investigación (Ministerio de Economía, Industria y Competitividad) y el Fondo Europeo de Desarrollo Regional (FEDER), y "La herencia de los Reales Sitios: Madrid de Corte a Capital (Historia, Patrimonio y Turismo)», ref. H2015/ HUM-3415, financiado por la Comunidad de Madrid y el Fondo Social Europeo. 
además la dinamización de la producción y el comercio de las artes y las manufacturas más allá de las bellas artes.

Palabras clave: artes decorativas; adorno de interiores; vida cotidiana; prensa; siglo XVIII.

ABSTRACT: Home decoration in late eighteenth century Spain experienced substantial changes as a result of the new customs and practices demanded by modern urban sociability. This new dimension took home as a stage for everyday life, an environment of representation assembled under the dictates of "good taste" and fashion. Never before it had been more necessary to keep abreast of fashion developments and the press played an important role in the diffusion of them, helping us in the rediscovery of those disappeared contexts. From the Diario de Madrid it is possible to know and understand the importance that ornamenting had among those people who wanted to be part of modern life. This eagerness promoted both, production and trade of arts and manufactures beyond the Fine Arts.

Key words: decorative arts; home ornament; everyday life; press; 18th century.

La apertura de nuevas dimensiones de estudio en torno al hecho cotidiano desde lo material ha ido cobrando mayor peso en la historiografía de la Edad Moderna, lo que ha ayudado a tener un conocimiento cada vez más preciso de los diferentes tipos de bienes que formaron parte de la vivienda en distintos momentos de su historia, así como sobre los usos, hábitos y significados que esos objetos tuvieron en la vida de las gentes, incluidos, claro está, los artísticos. El interés que ha despertado su análisis desde los estudios culturales, la historia social o la antropología ha hecho posible consolidar una pujante corriente historiográfica articulada en torno a la cultura material, la casa y lo doméstico, ese espacio habitado y social donde se pueden descubrir las múltiples y variadas interacciones que los individuos experimentaron en el pasado entre sí y con sus objetos, siendo además una de las principales señas de identidad de la vida urbana moderna que se abrió paso en el transcurso de la centuria ilustrada ${ }^{1}$.

Cuando trasladamos estas cuestiones al marco de la historia del arte, lo primero que salta a la vista es que, al menos en España, apenas hay investigaciones desde estos planteamientos. Probablemente, uno de los motivos es que la aproximación a estos materiales desde la disciplina ha sido problemática desde

1. Para el estado de la cuestión sobre la vida cotidiana, la vivienda y lo doméstico, véanse los trabajos de Franco RuBio, Gloria. "La historia de la vida cotidiana en la historiografía modernista española: algunas reflexiones». En FrANCO RuBIO, Gloria (coord.). La vida de cada día. Rituales, costumbres y rutinas cotidianas en la España Moderna. Madrid: Asociación de Cultura Almudayna, 2012, pp. 17-66; y «La vivienda en el Antiguo Régimen: de espacio habitable a espacio social». Chronica Nova, 2009, 35, pp. 63-103. 
un principio pues, a pesar de ser valoradas historiográficamente, han pasado a integrarse en un cajón de sastre con denominaciones tan diversas como artes decorativas, artes suntuarias, artes menores, artes aplicadas o artes industriales ${ }^{2}$. $\mathrm{Al}$ afrontar su estudio casi siempre de modo fragmentado es difícil recuperar los ambientes y escenarios donde estos objetos cobran sentido por el significado que tuvo su presencia en los mismos ${ }^{3}$. Así pues, durante los últimos años se ha avanzado enormemente en la investigación parcial de asuntos como el mobiliario, la platería o los textiles, tratando además de insertar su estudio en los discursos, métodos y enfoques de la disciplina.

Otro aspecto que tampoco parece haber ayudado a la puesta en valor de este patrimonio es su consideración como manufacturas, esto es, como productos y actividades excluidos sistemáticamente de la categoría de las bellas artes. Nunca formaron parte de ellas ni por las prácticas, ni por las tipologías, los materiales o las funciones, a pesar de que se consideraron hijas del dibujo y condicionaron enormemente el devenir de la Academia de San Fernando y la formación del artista en España. Esta contradicción la ilustraba con claridad Juan Agustín Ceán Bermúdez, quien, en una carta dirigida a Bernardo Iriarte en 1803, expresaba malhumorado que el entonces secretario de la Academia, Isidoro Bosarte, le había dicho que su Diccionario histórico de los más ilustres profesores de las Bellas Artes en España tenía

mal despacho porque los profesores le desacreditan diciendo que he mezclado en él los pintores y escultores con los vidrieros, plateros, bordadores, grabadores y rejeros, que son gente de otra estofa ${ }^{4}$.

Esta distinción ha prevalecido en aquellas artes que no lograron sacudirse su condición gremial, pese a que entonces pudieran tener la misma o mayor consideración, como es el caso del arte de la tapicería en relación con la pintura en la

2. Asentados en la literatura especializada en el transcurso del siglo XIX, estos términos siguen identificando a día de hoy el campo de estudio, sin que todavía se haya llegado a problematizar esta situación. VEGA, Jesusa. «La Historia del Arte y su devenir en España. Circunstancias y reflexiones desde la práctica subjetiva». En Molina, Álvaro (ed.). La Historia del Arte en España. Devenir, discursos y propuestas. Madrid: Ediciones Polifemo, 2016, pp. 21-174 (p. 72).

3. Esta fragmentación se proyecta en las obras colectivas donde cada estudioso se ocupa de su especialidad, lo que no impide que algunas sean de referencia: Bonet Correa, Antonio (coord.). Historia de las artes aplicadas e industriales en España. Madrid: Cátedra, 1982, o ARrAIZA, Alberto B. (dir.). Las artes decorativas en España. Summa Artis: Historia general del Arte. Madrid: Espasa Calpe, 1999, vol. 45 (2 tomos).

4. Crespo Delgado, Daniel. "Lectura y lectores en la España de la Ilustración. El caso de la literatura artística». Cuadernos de Historia Moderna, 2007, 32, pp. 31-60 (p. 43). No olvidemos que para Ceán Bermúdez esta decisión había sido plenamente deliberada: en el prólogo de su obra ya advertía que el lector encontraría no solo la noticia de artistas distinguidos «en la pintura y la escultura, sino también la de los miniadores, grabadores en hueco y de láminas, plateros, imagineros en vidrio y bordado, y hasta de los rejeros; porque no quise negar su justo elogio a ninguna de aquellas artes, en que cualquier modo pueden brillar el genio y la pericia del dibujo». 
Edad Moderna 5 . Hasta fechas relativamente cercanas, las pocas excepciones en las que se abordaban las artes decorativas como una realidad de conjunto se debían, no por casualidad, a investigaciones destinadas a recuperar la historia de edificios, casas y palacios singulares, si bien se entendía el espacio doméstico como un contenedor donde prevalecía la jerarquía de las artes y el criterio estilístico ${ }^{6}$. Recientemente la historia del arte ha empezado a incorporar nuevas preocupaciones y herramientas de análisis derivadas de los intereses de la cultura material y los estudios de vida cotidiana en torno a la vivienda. Cuestiones relativas al uso del mobiliario, la búsqueda del confort y la comodidad, los criterios del buen gusto, las problemáticas del lujo y la moda en el adorno doméstico, o la utilización de los espacios de la casa en función de los sexos, usos, modas y costumbres de la moderna sociabilidad, forman parte ya del campo de estudio en general, y de las investigaciones del siglo XVIII en particular ${ }^{7}$.

En lo que respecta a las fuentes, para el estudio de estos asuntos los documentos notariales -cartas de dote, inventarios, testamentos, contratos, facturas, escrituras de compraventa, etc.- son esenciales, pues entre la diversidad de objetos que se anotan se encuentran los que componían los escenarios cotidianos de representación dentro del hogar, y en las altas esferas cortesanas también se da con frecuencia noticia de los adornistas que prestaron sus servicios ${ }^{8}$. Existen otras

5. Sobre las valoraciones en torno al tapiz en su devenir historiográfico, HERRERO CARRETERO, Concha. "La historiografía francesa y la colección real de tapices de España». e-Spania. Revue interdisciplinaire d'études hispaniques médiévales et modernes, 2016, 23 [en línea]: https://e-spania.revues. org/25324.

6. Sirvan de ejemplo dos estudios todavía de referencia sobre la decoración interior del siglo XVIII en el contexto cortesano: EZQuerRa DEL BAYo, Joaquín. El Palacete de la Moncloa: su pasado y su presente. Madrid: Sociedad Española de Amigos del Arte, 1929, y JunQuera Mato, Juan José. La decoración y el mobiliario de los palacios de Carlos $I V$. Madrid: Organización Editorial, 1979.

7. Véanse, entre otros: ABAD-ZARDOYA, Carmen. "La vivienda aragonesa de los siglos XVII y XVIII. Manifestaciones del lujo en la decoración de interiores". Artigrama, 2004, 19, pp. 409-426; La casa y los objetos. Espacio doméstico y cultura material en la Zaragoza de la primera mitad del XVIII. Zaragoza: Caja de Ahorros de la Inmaculada, 2005; y «La dimensión cotidiana y social del buen gusto. Espacios y objetos de sociabilidad en el siglo de la "civilización"». En ArCE, Ernesto Carlos et al. (eds.). Simposio Reflexiones sobre el gusto. Zaragoza: Institución Fernando el Católico, 2012, pp. 17-184. CÁmarA, Alicia. "La dimensión social de la casa». En Blasco EsQuivias, Beatriz (dir.). La casa. Evolución del espacio doméstico en España. Madrid: Ediciones El Viso, 2006, vol. 1, pp. 125-199. Creixell CabezA, Rosa M. Noblesa obliga. L'art dela casa a Barcelona (1730-1760). Perpiñán: Presses Universitaires de Perpignan, 2013. MARTíNEZ ALCÁZAR, Elena. "Los espacios públicos de las viviendas acomodadas del siglo XVIII a partir de la documentación notarial de Murcia y Madrid». Atrio, 2011, 17, pp. 91-102. Subirana, Rosa Maria y TRIADó, Joan-Ramon. "Recuperació económica i producció artística. La decoració mural de les cases i palaces barcelonins al darrer terç del segle XVIII». En CANALDA, Silvia; NARVÁEz, Carme y SuREDA, Joan (eds.). Cartografías visuales y arquitectónicas de la modernidad. Siglos XV-XVIII. Barcelona: Universitat de Barcelona, 2011, pp. 113-134. Todos con actualizada y abundante bibliografía.

8. Algunos de gran relevancia como el francés Jean-Démosthène Dugourc, estudiado en profundidad por López CASTÁN, Ángel. "Jean-Démosthène Dugourc, adornista y arquitecto de la Corte de España (1786-1813)». En Martínez Millán, José; Camarero Bullón, Concepción y Luzzi TrafiCante, 
fuentes que complementan la información de archivo como es la prensa. Aunque pierde su carácter nominal -rara vez se conoce el nombre del que ofrece el servicio o del destinatario que se beneficia del mismo-, permite en contrapartida hacerse una idea de las dinámicas generales que movilizaban este tipo de actividades y aquellas que parece que contaban con el favor del público con poder adquisitivo para demandarlas, esa parte de la población que quizás no tenía títulos nobiliarios pero gozaba de holgura económica, desde banqueros y grandes comerciantes a subalternos donde se sitúan artistas, artesanos, menestrales, etc. En las siguientes páginas vamos a interesarnos por los cambios que tuvieron lugar durante la última década del siglo XVIII en Madrid -años del reinado de Carlos IV en los que se llegará a dar la mayor eclosión en la venta de artículos de lujo y la sofisticación en el gusto de las artes- siguiendo el rastro a la información contenida en las páginas del exitoso Diario de Madrid ${ }^{\text {, }}$, siendo conscientes de que en estos asuntos ni siquiera este diario fue el principal canal de información en la ciudad, pues parece que el boca a boca y los carteles que se colgaban, principalmente en la Puerta del Sol, eran medios más eficaces.

El hecho de abordar el entorno doméstico a través del periódico proporciona una información de extraordinaria riqueza. Permite recuperar los productos, los artífices o las técnicas empleadas en el adorno y la comodidad de la casa, así como comprender el papel que jugaron las artes en las prácticas cotidianas de producción, consumo y recepción de este tipo de bienes. Desde esta perspectiva, asumimos la decoración como un fenómeno de similar relevancia a la habitabilidad, domesticidad y sociabilidad, elementos clave en el análisis de la vivienda desde una aproximación cultural y materia ${ }^{10}$. Buen ejemplo de partida para mostrar la diversidad de matices que aporta la prensa puede ser algo tan cotidiano y necesario en materia de habitabilidad y confort como la calefacción. Cuando revisamos los anuncios del periódico publicados durante esa década de final de siglo, comprobamos que la estufa fue el artículo más ofertado, imponiéndose sobre otros más tradicionales como el brasero, común hasta entonces en la práctica totalidad de las casas españolas, o la chimenea de fábrica, reservada por lo general a las salas principales de las viviendas de mayor poder

Marcelo (coords.). La corte de los Borbones: crisis del modelo cortesano. Madrid: Ediciones Polifemo, 2013, vol. 3, pp. 2073-2139.

9. Publicado desde 1786 bajo el título de Diario curioso, erudito, económico y comercial, su difusión alcanzó un éxito notable a juzgar por su número de suscriptores y continuidad. Parte de su éxito radicaba en ofrecer a sus lectores artículos breves de divulgación científica y literaria, crítica de costumbres, noticias de actualidad y, en el ámbito que nos ocupa, útil información de carácter comercial como los avisos de oferta y demanda de empleos o los anuncios de novedades de artículos y productos. LARriBa, Elisabel. El público de la prensa en España a finales del siglo XVIII (1781-1808). Zaragoza: Prensas de la Universidad de Zaragoza, 2013, p. 163.

10. Véase el detalle de estas propuestas metodológicas en Franco RuBIO, Gloria. "La vivienda en el Antiguo Régimen...", op. cit., pp. 67 y ss. 
adquisitivo $^{11}$. Así pues, según las necesidades y presupuesto de los compradores, se podían encontrar sencillas "estufas de barro para calentar salas y gabinetes, de diferentes tamaños y precios", como las que se vendían por encargo en la fábrica de alfarería situada en el corralón de San Isidro ${ }^{12}$, o más elaboradas como las «dos estufas de barro de moda, vidriadas y pintadas" que se daban con equidad en la casa nueva de la calle de San Juan $(D M, 16 / 12 / 1791)^{13}$. Aunque menos comunes, también se ofertaban "estufas de hierro, buenas y vistosas, cubiertas o no cubiertas de loza o vidriado en la calle angosta de San Bernardo" (DM, 19/12/1793), o enteramente de metal como la "chimenea de bronce forrada de hierro con sus correspondientes cañones» que se vendía en el cuarto bajo del número 10 de la calle de la Sartén (DM, 09/03/1798) y la "chimenea francesa de hierro vaciado y su adorno de latón» que se daba con equidad en la cerrajería situada frente a la fuente de San Antonio de los Portugueses (DM, 28/10/1799). Si atendemos a las cualidades que se podían esperar de estos productos a tenor de sus descripciones, primaban casi a partes iguales los principios de utilidad y belleza: en cuanto a la primera, una buena estufa debía ser cómoda, segura y fácil de usar, así como tener un bajo consumo de combustible, repartir uniformemente el calor y mantener la estancia libre de humos y olores ${ }^{14}$. Respecto a la dimensión estética, no solo se describían vistosas, exquisitas y de buen gusto, sino que también debían llegar a ser consideradas objetos de adorno por sí mismas, pues en el fondo no dejaban de ser una pieza más del mobiliario de la casa que debían encajar con el resto de la decoración de la sala donde se instalasen, como por ejemplo,

Las estufas de loza, venidas de Francia, con sus ricas columnas y remate, las cuales dan más calor que los braseros, propias para colocar en un despacho, sala o salón, y sirven de adorno y de guarnición a donde se coloquen (DM, 11/01/1799).

11. En las casas más modestas, la principal fuente de calor seguía siendo, como en siglos anteriores, el fuego del hogar, también denominado chimenea según el Diccionario de la Real Academia Española de 1791: «hogar, o fogón para guisar, o calentarse, que tiene un cañón por donde sale el humo".

12. Diario de Madrid [en adelante, DM], 23/10/1789.

13. El mismo fabricante anunciaba un año más tarde la venta de estufas de barro de varios tamaños y precios así para leña como para carbón siendo estas últimas muy cómodas por su construcción y tamaño para celdas de religiosos, estudios de abogados, y otras piezas pequeñas; su colocación fácil y de poco gasto, no necesitando mucha cañería de hierro u ojadelata para el tufo del carbón, pudiéndose hacer uso de ellas sin caño si se quiere», muestra de la versatilidad de espacios donde podían instalarse $(D M, 06 / 12 / 1792)$.

14. Un modo de ahorrar en el consumo de leña era instalar estas estufas en el mismo espacio de las chimeneas francesas de obra: "Don Natalio Ubaneta, profesor artífice, que vive en la calle de la Puebla, casa sin n. entre el 23 y 24, hace presente al público cómo construye unas nuevas estufas a la americana, aunque sea en el mismo cañón de la chimenea, pues de este modo se quita el humo, y con poca leña se calienta mucho la pieza: el caballero que quiera valerse de su utilidad, acudirá a dicha casa, que se le servirá con la mayor prontitud y equidad posible» (DM, 25/11/1797). 
Otro aspecto central descrito en la prensa tiene que ver con los avances tecnológicos introducidos en el mercado, algo que no solo afectaba al modo de fabricarlos y decorarlos, sino también a su propio mantenimiento, cuestión clave si consideramos el elevado número de incendios del periodo ${ }^{15}$. La prensa proporciona valiosas noticias sobre los modos de trabajo de los artífices, así como sobre las diferentes estrategias con las que reclamar la atención de sus potenciales clientes. El más relevante en el tema que nos ocupa fue el napolitano Raymundo Yaneli, tanto por el volumen de anuncios y avisos aparecidos en el Diario de Madrid y la Gaceta de Madrid durante más de doce años, como por ser representativo de las habilidades y trabajos que podía acometer un artífice competente.

Yaneli se presentaba a sí mismo al público como «teórico y práctico del noble Arte de la Arquitectura", "profesor de Arquitectura" o simplemente "Arquitecto", resaltando así su distinguida condición social como artista liberal que presta sus servicios en la corte ${ }^{16}$. La revisión de los detallados anuncios publicados entre 1791 y 1803 permite conocer sus progresos, de los que se mostraba orgulloso, a resultas de las investigaciones empíricas y científicas que había hecho sobre la calefacción, orientadas hacia nuevos materiales para su construcción, artilugios para expandir el calor por otras estancias ${ }^{17}$, instalación y reparación de toda clase de estufas y chimeneas..., todo con garantía de seguridad y salubridad, mejorando a su vez la prevención de incendios ${ }^{18}$. Su condición de arquitecto le llevó a compaginar estos quehaceres con otras tantas tareas relacionadas con el mantenimiento

15. Prueba del interés por las novedades de esta clase de productos son las noticias que la prensa incluía regularmente del extranjero sobre nuevos estudios e ingenios, como la publicación en Inglaterra de los trabajos de John Whitehurst, que incluía un «tratado sobre las chimeneas, la ventilación y la construcción de estufas, anunciada al público en 1782» (DM, 12/12/1792).

16. Desconocemos cuál era la formación de Yaneli, aunque las escasas noticias biográficas parecen indicar que en los años previos a la publicación de los anuncios se dedicó a labores de albañilería y oficios vinculados a la construcción. Conviene recordar que todavía durante el siglo XVIII el término artista designa por igual a "aquel que crea de nuevo" y al "artesano»; será precisamente en este siglo cuando se establezca la jerarquía entre "artesano", aquel que solo fabrica, y "artista», el que fabrica y piensa (SICARD, Monique. La fabrique du regard. París: Éditions Odile Jacob, 1988, p. 31). Sobre esta cuestión véase también CASTRO CuENCA, Jesús. "Los artistas en el siglo XVIII: reflexiones en torno a un concepto". Hispania, 1994, LIV/2, 187, pp. 505-556.

17. En uno de sus primeros anuncios explicaba cómo había «notado que las estufas de hierro, barro cocido, y de otros metales, calientan sólo una pieza; y con alguna incomodidad para su colocación, ha construido otras estufas nuevas de un material compuesto y de mucha duración, que no solamente con poco consumo de leña dan mucho calor a la pieza en donde se halla, sino que si se quiere hará ir el calor a otra pieza o piezas, pisos altos o bajos, con la misma lumbre de dichas estufas, y libre de incendios y de humos" (DM, 18/01/1793). Parece que estas técnicas las había mejorado tres años más tarde, cuando ofrecía "una exquisita y nueva invención de chimeneas inglesas, y estufas, así con el beneficio de mucha consistencia, como la útil ventaja de caldear la pieza donde se halle con poco consumo de leña" (DM, 23/01/1796).

18. Así pues, el 1 de noviembre de 1798, hacía saber al público «que con su infatigable estudio teórico y práctico, ha conseguido para siempre, sin duda alguna, quitar del todo el defecto del humo a todos aires, y sin peligro de incendios, en toda clase de chimeneas y estufas, en cualquier situación 
general de los edificios como quitar la humedad, "de donde quiera que provenga", o hacer desaparecer los malos olores de "pozos, minas y otros parajes", dejando constancia de cómo «todo lo referido lo tiene acreditado en esta corte, en varias casas de señores y particulares», muestra en definitiva de su reconocimiento público y aceptación (DM, 30/12/1801).

Como se puede comprobar a tenor de lo expuesto, el periódico permite, por su condición efímera, rememorar el pasado desde lo inmediato, pudiendo observar a la vez tanto una realidad en transformación como la aparición de nuevas realidades ${ }^{19}$. De este modo, sus páginas se convertían en un espacio que genera información, educación y debate. Desde estas tres variables se puede comprender cómo el público no solo podía conocer las novedades que tenían lugar en el adorno de la vivienda, sino también acceder a una formación en materia de buen gusto, necesaria para disponer de una opinión contrastable. La relevancia de todo ello reside, como ha señalado Román de la Calle, en que el buen gusto era una parte esencial y cotidiana de las nuevas experiencias estéticas y expresivas que definían la manera de proyectar la apariencia hacia los demás y formar así parte de las nuevas redes de la sociabilidad ${ }^{20}$, hecho comprendido como la propensión natural que todo ser humano tenía de agradar al buscar el trato social con los demás, esto es, de hacer amable y agradable la vida en sociedad ${ }^{21}$. La consecuencia es que este fenómeno no solo definió los comportamientos y actitudes diarias del sujeto y su familia, sino que se extendió igualmente a los espacios en los que se desenvolvía y donde proyectaba su identidad, definiendo así una nueva distribución de la casa -ahora abierta a la visita de amigos y conocidos-, cuya decoración debía responder a los códigos del buen gusto que dictaba la moda según el decoro que correspondía a cada clase.

que se hallen; con la particularidad que se conserva la lumbre, y da mucho calor a la pieza, lo cual consiste en el modo de sus construcciones".

19. Esto respondería a la doble naturaleza activa y pasiva que caracteriza al periódico como fuente histórica: SÁIZ García, Dolores y FuENTES, Juan Francisco. "La prensa como fuente histórica». En Artola, Miguel (dir.). Enciclopedia de la Historia en España. Madrid: Alianza Editorial, 1993, vol. 3, p. 528. En este sentido, hacemos nuestras estas cuestiones metodológicas en torno a la prensa, recogidas junto a otras consideraciones vinculadas a lo cotidiano por RAMOS SANTANA, Alberto. "La vida cotidiana en el Cádiz de las Cortes. El recurso de la prensa como fuente para su estudio». En Cantos CaSENAVE, Marieta; Durán López, Fernando y Romero FERrer, Alberto (eds.). La guerra de pluma. Estudios sobre la prensa de Cádiz en el tiempo de las cortes (1810-1814). III. Sociedad, consumo y vida cotidiana. Cádiz: Universidad de Cádiz, 2008, pp. 22-101.

20. De la CALle, Román. "Gusto y cotidianidad: una puntual mirada histórica». Ars Longa, 20052006, 14-15, pp. 265-270. Sobre cómo estas experiencias estéticas determinaron los nuevos estilos de vida y costumbres sociales según iba avanzando la centuria es clave la obra de SEOANE, Julio. La politica moral del Rococó. Arte y cultura en los orígenes del mundo moderno. Madrid: Antonio Machado Libros, 2000.

21. Molina, Álvaro. Mujeres y hombres en la España ilustrada. Identidad, género y visualidad. Madrid: Cátedra, 2013, pp. 277 y ss. 
ADORNO Y REPRESENTACIÓN: ESCENARIOS COTIDIANOS DE VIDA A FINALES DEL SIGLO XVIII EN MADRID

El buen gusto será, de hecho, una de las alusiones más reiteradas en los anuncios y avisos de la prensa de estos años, bien fuera para llamar la atención sobre bienes y utensilios, bien para resaltar el buen hacer de un artista o para hacer más atractivo el alquiler o venta de una casa. En el primer caso, podemos poner como ejemplo el surtido que en su momento llegó a la librería de la oficina del Diario de Madrid de

nuevos papeles de tapicería completa de especial dibujo y buen gusto, según se estila en el día en la Corte de Madrid: cada colgadura se compone de diferentes piezas, que juntas hacen agradable la vista en sus paños, frisos, cenefas y demás guarniciones (DM, 15/11/1791).

Como se puede apreciar, los requisitos que debían reunir los productos considerados con tal distinción eran: la alusión al "especial dibujo", que determina su originalidad y naturaleza artística; su condición de novedad a la última moda, "Según se estila en el día»; por último, la finalidad del conjunto cumplía las normas implícitas de la sociabilidad, pues el adorno se destinaba a "hacer agradable la vista" del interior.

No obstante, los cambios que se estaban operando en el adorno de la casa venían siendo objeto de debate y controversia, sobre todo por el lugar que ocupaban las bellas artes, que algunos veían cómo eran desplazadas por las nuevas manufacturas, las cuales nunca podrían llegar a su altura en opinión de muchos ilustrados. Por ejemplo, Ponz ya se lamentaba, en la primera edición de su Viaje de España, de la pérdida gradual entre la nobleza madrileña del hábito de coleccionar buenas pinturas a consecuencia de «la moda, por no decir la locura, de despojar sus casas de estos apreciables ornamentos, estimando en más una enfilada de piezas cubiertas de tejidos, y ridículas tallas, en que nada hay que alimente la imaginación ${ }^{22}$. Esta opinión era compartida por Jovellanos, quien pocos años después escribía:

Pinturas, estatuas, vasos y otras preciosidades, que antes adornaban los grandes edificios, iban saliendo de ellos poco a poco, y en su lugar entraban las telas, el oro, los cristales y otros adornos, sustituidos por la moda y el capricho. Desde entonces empezamos a ver con hastío la sencillez de nuestros padres; y cansados de lo que ellos habían tenido en grande estima, feriamos los adornos de moda al cambio de las mejores producciones de las artes ${ }^{23}$.

22. Ponz, Antonio. Viaje de España, en que se da noticia de las cosas más apreciables, y dignas de saberse, que hay en ella. Madrid: Imprenta de Joaquín Ibarra, 1776, tomo V, pp. xvii-xviii.

23. Jovellanos, Melchor Gaspar. Elogio de las Bellas Artes. Madrid: Casimiro Libros, 2014 [1781], pp. 86-87. Para conocer desde la misma perspectiva de la prensa la decoración de los interiores domésticos en las décadas previas, véanse los trabajos de VEGA, Jesusa. "Contextos cotidianos para el arte. Cuadros y objetos de arte para el adorno doméstico madrileño a mediados del siglo XVIII. Revista de Dialectología y Tradiciones Populares, 2000, LV/1, pp. 5-43, y «Transformación del espacio doméstico 
Entre el catálogo de "adornos de moda» que se anunciaba en la prensa durante los años noventa, podemos encontrar la vigencia que aún tenían las ricas colgaduras de sedas y damascos, a juego con los cortinajes y entapizado de las sillerías, con las que se vistieron las paredes las décadas previas ${ }^{24}$. Sus diseños se acabaron transfiriendo -como veremos luego-, a los papeles pintados y, seguidamente, a la decoración mural de salas y gabinetes. Un establecimiento destacado era la fábrica de colores y papeles estampados de la calle Calatrava donde, entre otros productos y servicios asociados al adorno completo de una sala, se ofrecían con la mayor equidad

pilastras, frisos, cornisas, molduras, y demás perteneciente al orden arquitectónico, papeles, cenefas, y medallas, con figuras grandes y chicas, arabescas o grotescas, y etruscas, papeles imitando damascos, chinas y demás telas de seda, con cenefas y frisos correspondientes: el fabricante acudirá a las casas donde le llamen, para vestir y adornar los cuartos, según el gusto y género de adorno que se le prevenga; pinta asimismo al temple las habitaciones, en las cuales no quieran poner papel; vende colores molidos y preparados para pintar al fresco y al temple; no crían ni admiten chinches los papeles pegados por dirección de dicho fabricante, por cierta droga que emplea $(D M, 12 / 12 / 1793)$.

El texto es suficientemente ilustrativo de la diversa combinación de asuntos y motivos que formaron el gusto moderno en torno al adorno, al que también podemos acercarnos a través de los anuncios del mercado inmobiliario de alquiler, que proporcionan útil información para conocer otros aspectos como la distribución interior de las viviendas madrileñas. Informar sobre los adornos de las casas era un buen reclamo para atraer a posibles inquilinos, pensemos en el "cuarto principal amueblado, con cortinas, canapé y sitiales de damasco de seda, con espejos de cuerpo entero, cornucopias y otros adornos y muebles» que se alquilaba en el número 12 de la calle de San Marcos, sin dar apenas información sobre su distribución, salvo que disponía de «7 piezas cómodamente repartidas» ( $D M$, 16/06/1788). Lo normal, sin embargo, no era describir los adornos y muebles de forma tan detallada, sino usar fórmulas más genéricas como por ejemplo: el cuarto que contaba con "sala, alcoba y gabinete, y otras diferentes piezas, todas bien adornadas para cualquier persona distinguida, aunque tenga familia» de la calle de

en el Madrid del siglo XVIII: del oratorio y el estrado al gabinete». Revista de Dialectología y Tradiciones Populares, 2005, LX/2, pp. 191-226.

24. "En la calle de Hortaleza, n. 4 frente de la fuentecilla, en la tienda de tapicería de Aniano Crevier darán razón de una colgadura para sala, de damasco amarillo, que tiene 39 paños de a 4 varas de largo, que hacen 169 y varias cortinas de lo mismo que componen 64 varas", que en este caso se ofertaban además a juego con "18 sillas, 2 canapés y 12 taburetes compañeros y del mismo damasco» (DM, 13/11/1786). Otro ejemplo similar más tardío sería la colgadura de «24 paños, de más de media vara, con cenefa, fondo raso de color de caña, bordada de cordoncillo, con sobrepuestos de terciopelo de varios colores, en buen dibujo que se vendía en la tienda de fideos y puesto del cotillero de la calle de Toledo" (DM, 27/11/1794). 
ADORNO Y REPRESENTACIÓN: ESCENARIOS COTIDIANOS DE VIDA A FINALES DEL SIGLO XVIII EN MADRID

la Cruz (DM, 07/05/1789); «el cuarto bajo grande, amueblado, y guarnecido todo de papel fino y de mucho gusto" que se permutaba "en las inmediaciones de la Carrera de San Jerónimo, Puerta del Sol, y calle del Príncipe» (DM, 23/07/1792); «el cuarto principal que se alquila en una de las mejores calles, el cual está adornado y con pinturas de buen gusto", del que se daba razón en el mismo despacho del Diario de Madrid (24/07/1793); o la "habitación pintada a la moderna y bien alhajada para un caballero o dos, con asistencia o sin ella", disponible en el cuarto bajo del número 11 de la calle de la Ballesta (DM, 09/08/1794) ${ }^{25}$.

Independientemente de la fórmula elegida para vestir las paredes, los interiores se remataban con zócalos, frisos, cenefas y molduras siguiendo la moda del día. Lo habitual es que fueran de madera o estuco, pintándose o dorándose posteriormente en función también del acabado de puertas y ventanas, que se embellecían a su vez con cristales y vidrieras ${ }^{26}$. Todos estos elementos determinaban, en definitiva, el efecto de esplendor, riqueza y buen gusto que se esperaba de cualquier "sala bien adornada", como las que formaban parte de este cuarto principal en la calle Montera, donde se hallaban disponibles "las piezas siguientes y alhajadas con asistencia o sin ella»:

Un recibimiento, una antesala, una sala grande pintada, a cielo raso con su buena moldura por todo alrededor con dos balcones a la calle con su gabinete pintado y con su moldura, con su balcón a la calle con su alcoba pintada con su retrete y 3 piezas más para criados, cocina y despensa, la cocina con todo lo necesario competente para ella; en dicha casa también se puede proporcionar lugar para tener un coche con sus mulas o caballos (DM, 30/07/1799).

Otro elemento de distinción que podemos resaltar de este cuarto en alquiler es que tanto la sala principal como el gabinete, es decir, las habitaciones de respeto destinadas al recibimiento de las visitas, disponían de balcones que daban a la calle, lo cual no solo proporcionaba buena luz y ventilación, sino también la posibilidad de disfrutar de las vistas a la ciudad. Así sucedía con el cuarto principal que años atrás había ocupado el embajador de Marruecos, que se anunciaba "con buena porción de piezas a la parte norte y mediodía, con agradables vistas y aires

25. Los destinatarios de los anuncios de alquiler serán, lógicamente, caballeros -con o sin familia a su cargo-, lo que nos habla de un adorno que venía a diferenciar por estatus, estado social y sexo. Sobre este último aspecto véase GONZÁLEZ HERAS, Natalia. "Sexo femenino y niveles de actuación sobre la materialidad de la casa en el Madrid del siglo XVIII». En Franco RubIO, Gloria y PÉrez SAMPER, María Ángeles (eds.). Herederas de Clío. Mujeres que han impulsado la Historia. Homenaje a M. ${ }^{a}$ Victoria López-Cordón Cortezo. Sevilla: Mergablum, 2014, pp. 235-249.

26. También eran frecuentes los anuncios de materias primas como «la partida de piedra de mármol de diferentes canteras de España, para hacer mesas, chimeneas, o solados de iglesia" que vendía un vecino en la calle de la Madera alta ( $D M, 13 / 12 / 1791)$, o de productos ya manufacturados y que se podían reutilizar, como «algunas puertas, y ventanas enrasadas y entre ellas algunas moldadas a la francesa, como asimismo bastidores de ventanas, y puertas vidrieras, todo casi nuevo y muy servibles» que se hallaban en la Real Casa Almacén de Cristales de la calle del Turco (DM, 28/05/1791). 
puros» en las proximidades de la Puerta de Fuencarral (DM, 30/10/1795), y con «el cuarto segundo acabado de pintar al mayor gusto, el que consta de 10 piezas dispuestas en la mejor comodidad, dando unas vistas con dos balcones a la calle del Gobernador y otras con 3 balcones a la de Verónica»; este último se encontraba en una casa nueva con portal en la calle Fúcar (DM, 03/08/1799).

Balcones y vistas permitían conectar el entorno doméstico con la propia vida de la ciudad, pues, a fin de cuentas, ambos espacios conformaban un escenario común en las prácticas de sociabilidad que diluyen las barreras entre las esferas de lo público y lo privado, sin olvidar que la propia experiencia del adorno formaba parte de lo cotidiano también en las calles, paseos, plazas y jardines del entramado urbano ${ }^{27}$. Aquello que acontecía en la calle podía llegar incluso a ser parte del disfrute doméstico gracias al uso de los espejos que, instalados frente a las ventanas y con el grado adecuado de inclinación, podían reflejar el exterior como si se tratara de un cuadro efímero, y con la idea de "ver en ellos los edificios, los jardines y demás objetos que agradan a la vista ${ }^{28}$. Lógicamente, el espejo se llegaba a integrar perfectamente con las colgaduras y resto de muebles de la casa. Su uso en España había comenzado a extenderse desde mediados de siglo, formando parte de la decoración de las salas en razón de su adorno y utilidad, pues al margen de los efectos que se podían lograr en el ámbito de las ilusiones ópticas como las descritas, a las que posiblemente no todos pudieran acceder por falta de operarios cualificados en su montaje, también permitían completar la decoración con sus marcos y reflejos, mejorar la calidad de la iluminación de las estancias y servir como pieza de ostentación.

Del mismo modo, las prácticas simbólicas de representación asociadas al adorno no eran privativas del espacio doméstico, sino que se proyectaban igualmente fuera del hogar. Por un lado, mediante el propio adorno personal a través del traje, el aseo y los complementos con que se vestía cada individuo ${ }^{29}$; por otro lado, a través de aquellos artefactos que formaban parte del «ajuar de camino» ${ }^{30}$,

27. En el caso de la corte madrileña, el espacio más emblemático en cuanto al embellecimiento de la ciudad fueron las inmediaciones del Paseo del Prado, cuyas fuentes, puertas y adornos han sido estudiados por Lopezosa Aparicio, Concepción. El Paseo del Prado de Madrid. Arquitectura y desarrollo urbano en los siglos XVII y XVIII. Madrid: Fundación de Apoyo a la Historia del Arte Hispánico, 2006, pp. 205 y ss. Sobre los nuevos cambios en la concepción de la ciudad y el papel de la vivienda en la misma, véanse los trabajos de SAMBricio, Carlos. "Vivienda y crecimiento urbano en el Madrid de Carlos III". En Carlos III, Alcalde de Madrid. Madrid: Ayuntamiento de Madrid, 1988, pp. 381-448, y "Arquitectura, ciudad y territorio a finales de la Ilustración». Cuadernos Dieciochistas, 2016, 17, pp. 25-46.

28. La cuestión ha sido estudiada en profundidad en VEGA, Jesusa. Ciencia, arte e ilusión en la España ilustrada. Madrid: CSIC-Ediciones Polifemo, 2010, pp. 331-347.

29. Sobre esta cuestión, véanse los capítulos de la segunda parte de MoLINA, Álvaro y VEGA, Jesusa. Vestir la identidad, construir la apariencia. La cuestión del traje en la España del siglo XVIII. Madrid: Ayuntamiento de Madrid, 2004.

30. El término ha sido descrito por ABAD-ZARDOYA, Carmen. "Por tierra y mar. El ajuar de camino como proyección del espacio doméstico». Res Móbilis, 2012, 1/1, pp. 41-58. 
objetos que servían para proyectar socialmente la casa. En este sentido es probable que no hubiera nada más moderno durante los años noventa que las lujosas berlinas, coches y birlochos que personajes como Goya gustaban de conducir a gran velocidad por las calles de la corte ${ }^{31}$. Disponer de vehículo propio era, efectivamente, un signo de distinción que también participaba de las prácticas decorativas y los cánones del buen gusto, siendo muy habituales durante estos años los anuncios en los que se ofertaban diversos servicios de artífices como José Caminos, que doraba "toda clase de obras y molduras de coche" (DM, 27/11/1796); el "pintor, dorador y jaspista, imitador de maderas y charolista de coches", de quien daban razón en la calle del Prado, casa número 3 (DM, 22/10/1793), o «el pintor recién venido a esta corte que pinta orlas en coches y calesines» y que se podía encontrar «en la calle de León n. 19 cuarto bajo» (DM, 12/07/1797).

Ejemplo extremo de cómo el gusto por el adorno impregnó todas las facetas de la vida cotidiana hasta convertirse prácticamente en obsesión es el anuncio del libro titulado Arte de pintar y manchar los animales, con un método exacto para transformar los caballos blancos en pios, y poner asi a estos como a los perros de caza y falderos, manchas y fajas de diversos colores permanentes, sin padecer lesión alguna (DM, 18/06/1789). Su autor prometía reemplazar los accidentes de la naturaleza en el color de los animales para que estos pudieran brillar con luz propia de acuerdo a las tonalidades que se esperaba de cada uno de ellos según los dictados de la moda y el buen gusto, como el caballo cuatralbo, «en opinión de muchos más apreciable que uno castaño o negro"; el perro de caza manchado, que tenía "más estimación que otro que no lo sea", o el «lucero negro o blanco opuesto al color del resto de la piel de un faldero", perfección reconocida en cualquier mascota canina en el caso de las damas. El animal de compañía se convertía, de este modo, en otro elemento más que proyectaba la distinción social, formando parte de las prácticas cotidianas del adorno ${ }^{32}$.

Volviendo a los interiores domésticos y su decoración, cuando atendemos la cuestión de la distribución en los anuncios de alquiler, podemos hacernos una idea de la versatilidad de uso que tenían frente a los principios más estables y

31. GOYA, Francisco de. Cartas a Martín Zapater. Ed. de M. Águeda y X. de Salas. Madrid: Istmo, 2003, carta 81, p. 231.

32. Dupont, Carlos. Arte de pintar y manchar los animales variando ingeniosamente sus nativos colores. Madrid: s. i., 1789, pp. xii-xiii. También era frecuente el uso de animales disecados como adorno, como los que proporcionaba un «sujeto bastantemente hábil en la disección de aves, cuadrúpedos e insectos, de que tiene dadas varias pruebas en la formación de algunos curiosos Gabinetes de Historia Natural para sujetos particulares», que ofrecía "disecar cualquier animal de las especies insinuadas con el mayor esmero, particularmente si alguna señora le encargarse la disección de algún lorito, canario, perro fino o cualquier otro animalito, pues además de hacerlo con equidad, lo dejará cual si estuviera vivo» (DM, 06/08/1794). Sobre los múltiples usos, cuidados, conocimientos y utilización de los animales en este periodo véase GÓMEZ-CENTURIón JiMÉNEZ, Carlos. Alhajas para soberanos. Los animales reales en el siglo XVIII: de las leoneras a las mascotas de cámara. Valladolid: Junta de Castilla y León, 2011. 
fijos que se aconsejaban en los tratados de arquitectura y otras obras de literatura artística $^{33}$. Un perfil bastante habitual de inquilino en Madrid era el que acudía temporalmente por política o negocios. En función de su estatus, podían hacerse acompañar de su propio servicio, necesitando espacios acordes a su representatividad $^{34}$, bien comunicados y ubicados en zonas estratégicas de la ciudad. Así,

No muy lejos de Palacio, se alquila para uno o dos meses, con asistencia o sin ella, en el cuarto principal de una casa muy aseada con sala, alcoba grande, un gabinete, comedor, cuarto capaz para dos criados y uso de cocina, todo con muebles muy decentes, los utensilios necesarios y bellas luces en todas las piezas ( $D M$, $12 / 09 / 1789)^{35}$.

El hecho de alquilar un cuarto principal suponía abonar la renta más alta de un edificio, pues una característica de la vivienda en Madrid es que en un mismo inmueble podían convivir familias de distinta condición social y nivel económico; el alquiler era más asequible a medida que se ascendía en altura ${ }^{36}$. Si se viajaba solo y sin criados había opciones más modestas, como piezas en algunos cuartos en los que también se ofrecía dar servicio si el cliente lo deseaba. Esto era bastante habitual, así se tenían algunos ingresos extra, siendo frecuentes anuncios como el de la «señora viuda, con su casa muy adornada» que admitía «dos caballeros,

33. Por ejemplo, las propuestas de BAILs, Benito. Elementos de Matemática. IX. La arquitectura civil. Madrid: Imprenta de Joaquín Ibarra, 1783, sobre la distribución de los apartamentos de un palacio eran difíciles de encajar en la realidad de las viviendas de buena parte de la sociedad madrileña de la época. La revisión de la literatura artística y la historia de la arquitectura doméstica ha interesado a MARTínez MEDina, África. "La distribución a través de la teoría: difusión y aceptación de los nuevos esquemas distributivos". Espacio, tiempo y forma. Serie VII, Historia del Arte, 1994, 7, pp. 247-264. Estos planteamientos teóricos se han empezado a contrastar, por su lado, con las propias "biografías" de las casas y las experiencias de sus moradores; véase, por ejemplo, GonZÁlEz HERAS, Natalia. "Una casa y tres generaciones de moradores en el Madrid del siglo XVIII». En Franco Rubio, Gloria (coord.). Caleidoscopio de la vida cotidiana (siglos XVI-XVIII). Logroño: Siníndice, 2016, pp. 171-184.

34. No debemos olvidar que el servicio posibilitaba el buen funcionamiento de una casa y que, para los amos, los criados eran parte de ese engranaje doméstico, independientemente del espacio donde prestaran su función. Creixell Cabeza, Rosa M. Noblesa obliga..., op. cit., p. 31.

35. El hecho de que la corte se desplazara durante el año por los reales sitios hacía extensible la oferta de alquileres en las poblaciones correspondientes, como las viviendas que ofrecía don Benito Redondo en el Barrio Nuevo de Aranjuez frente a la huerta de Secano: "Se alquilan cuartos principales, segundos, bajos y terceros, adornados y con todo lo necesario para personas decentes por toda la jornada, por meses y días con comodidad, se acudirá a tratar de dicho ajuste en dicho sitio y casa de dicho D. Benito Redondo, y en Madrid casa n. 9 cuarto segundo en la calle de las Carretas donde vive Doña Francisca González» (DM, 05/05/1790).

36. En este periodo podían llegar fácilmente a cinco o seis alturas, haciendo evidente el problema de la falta de espacio de solares en la ciudad y en las propias viviendas; véanse al respecto García Felguera, María de los Santos. «La vivienda madrileña en los años de la Ilustración». Anales del Instituto de Estudios Madrileños, 1988, 25, pp. 299-310; y GONZÁlEz HeRAs, Natalia. "Vivienda e interiores domésticos en el Madrid ilustrado». En García Fernández, Máximo (coord.). Cultura material y vida cotidiana. Madrid: Sílex Ediciones, 2013, pp. 151-166. 
asistiéndoles con la mayor decencia y comodidad en la servidumbre y aseo; dará razón de esto Diego Navarro, cordonero que está en el portal de Santa Teresa junto a San Martín (DM, 13/05/1791), o simplemente el "de una señora» como la que vivía en la Puerta del Sol, que buscaba «uno o dos huéspedes a los que se le cederá una sala, gabinete y uno o dos cuartos; todas las piezas están perfectamente adornadas y darán asistencia» (DM, 12/10/1792).

La versatilidad de los espacios hacía variable el número de personas que podían alojarse en una misma casa, lo cual resultaba muy práctico cuando se debía alojar un grupo numeroso de individuos. Sirva de ejemplo la "familia de distinción, que quiere venir a divertirse a este pueblo una temporada», razón por la que buscaba «un cuarto principal amueblado o por amueblar en las inmediaciones de los Coliseos y Prado, y que dicho cuarto tenga lo menos nueve piezas útiles» (DM, 12/04/1792). La oferta de alquileres era variada, como igualmente lo era la demanda. En ocasiones se daba información precisa sobre el número de piezas que componían el cuarto, ayudando al futuro inquilino a imaginar las posibilidades de la casa:

Se alquila en la calle Ancha de San Bernardo junto a la fuente de Matalobos un cuarto principal en el esquinazo de la misma calle con vista para la del Norte, que consta de nueve piezas, sala de dos balcones, gabinete, con otra sobre la calle y alcoba, estos guarnecidos de papel, recibimiento, cuatro cámaras y una cocina con pozo dentro, pasillo \&c. la llave se hallará en el zapatero de viejo que vive en el portal y dirá el precio $(D M, 27 / 02 / 1791)$.

En otras ocasiones, por el contrario, apenas se detallaba la distribución interna, lo que hace pensar que bastaba con tener una idea de la capacidad, pues las formas de aprovechar el espacio dependían de las necesidades de cada inquilino ${ }^{37}$. Adornos, distribución de piezas y superficie disponible eran, en definitiva, tres variables a considerar a la hora de alquilar una vivienda, independientemente del número de miembros que fueran a habitarla. Un testimonio elocuente es el del caballero que se retiraba de la corte y era dueño de la casa número 22 de la calle de la Encomienda, donde ocupaba el «cuarto principal» que quería alquilar. Este se componía de:

recibimiento, sala, gabinete, alcoba, pieza de labor con alcoba, otros dos dormitorios, un despacho independiente, cocina, despensa, un desván con comunicación por la cocina, para seis carros de carbón, otro para esteras, muy capaz, sibil y pozo cuyo uso es por el corredor, desde el mismo piso; previniendo que cederá también el uso de los muebles, que se compone de dos espejos grandes, varias cornucopias,

37. «En los barrios de Portaceli, se alquila un cuarto principal muy decentemente amueblado y con cortinas de damasco de seda; es una habitación que cabe una familia aunque sean de 9 a 10 personas; dará razón el tapicero que vive en la calle de Jacometrezo, en el almacén que está pegado al Hospital de los franceses» (DM, 28/04/1789). 
diferentes pinturas de cobre, mesas, armarios, cofres, cortinajes, ajuar de cocina y de despensa, tres camas con sus colchones y una pequeña librería ( $D M, 03 / 11 / 1793)$.

Como se puede comprobar, el mobiliario era un factor relevante para entender la decoración de la vivienda, y no cabe duda de que la consolidación de fenómenos como el lujo y la moda en la década de los años noventa aceleró el proceso iniciado a mediados del siglo XVIII de deseo constante de renovación, que llevó a arrinconar todo lo antiguo. La consecuencia de esta transformación era que

si los muebles eran [hace treinta o cuarenta años] más costosos, también eran de mayor duración, y después de haber servido muchos años, se podía todavía aprovechar la materia de que se fabricaban: lo que no sucede con los papeles pintados, con las mesas, taburetes, canapés, y otros muebles, que se estilan en el día ${ }^{38}$.

Dado que muchas casas se ofertaban sin muebles, existía igualmente la opción de alquilar el mobiliario por separado. Sabemos que el suegro del pintor Luis Paret y Alcázar prestaba este servicio, como también el que tenía negocio en la calle de la Ruda número 6, donde había «tapices, cortinas, arañas, cornucopias, alfombras y ramos de hoja de lata todo decente» ( $D M, 25 / 04 / 1795)$, o «en el almacén de camas de alquiler de la calle de los Leones casa tienda n. 4 junto a la red de san Luis", en el cual también había "tapices, alfombras, biombos, braseros de azófar, cobre y yerro, con sus tarimas correspondientes, y todo mueble menaje de adorno de casa; también se venden de estos mismos efectos, varias mamparas, puertas vidrieras, lunas grandes y pequeñas de espejos para tremores, todo con equidad" $(D M, 30 / 10 / 1801)^{39}$.

Basta leer estas últimas descripciones para advertir la enorme variedad de objetos que podían componer el mobiliario de la casa, término cuyo uso no se registra hasta un siglo más tarde. Por su parte, la voz mueble remitía, según el Diccionario de la Real Academia Española (1791), al «adjetivo que regularmente se usa como sustantivo para expresar la hacienda, o bienes que se pueden mover y llevar de una parte a otra, a distinción de los que se llaman bienes raíces» ${ }^{40}$. Esta

38. SEmPere y GuARINos, Juan. Historia del lujo y de las leyes suntuarias en España. Madrid: Imprenta Real, 1788, vol. 1, p. 178. Este aspecto modificó igualmente la consideración dominante que se tenía hacia el producto de lujo en el entorno doméstico, que ya ni debía tener precios desorbitados, ni estar confeccionado con materiales nobles o ser diseñado para durar largo tiempo, como explica ABAD-Zardoya, Carmen. "La vivienda aragonesa...", op. cit., p. 413.

39. Pese a que, como decíamos antes, el brasero no era ya un artículo de moda en materia de calefacción, es indiscutible que su utilidad y facilidad de uso seguía haciéndolo indispensable durante el invierno, por lo que era habitual encontrar varios anuncios específicos ofertando su alquiler temporal como los «braseros de azófar y cobre con sus tarimas y jamúas y también murillos para las chimeneas» que estaban disponibles en la prendería de la calle de San Onofre ( $D M, 22 / 10 / 1796)$, o los «braseros de pie con sus badiles» ofertados en el cuarto principal del número 43 de la calle Caballero de Gracia (DM, 15/11/1797).

40. El jesuita Terreros y Pando, por el contrario, admitía otras voces complementarias que conectan más con el contexto de la decoración en el hogar, como, por ejemplo, «la alhaja movible para 
definición es de suma importancia para comprender cómo tanto las bellas artes como las manufacturas eran consideradas parte de un conjunto común de adornos en la casa, y prueba de ello es que se ofrecían normalmente juntas, tanto en los ya citados anuncios de alquiler como, sobre todo, en los avisos de almonedas que se publicitaban en la prensa. El interés de este último tipo de avisos es doble: en primer lugar, porque da una idea global sobre los enseres existentes en una casa de la época según la condición social de sus dueños; en segundo lugar, debido a que la imposibilidad de detallar el inventario completo de los bienes en el periódico obligaba a hacer una selección de aquello que se pensaba que podía tener una mayor demanda y atraer a posibles compradores ${ }^{41}$. Del centenar de anuncios que hemos seleccionado sobre noticias de almonedas a lo largo de la década, la pintura es el tipo de objeto que más veces aparece en las descripciones de los avisos, seguido de trajes, ropas y coches, particularmente berlinas. Tras ellos van las sillerías junto a cortinas y colgaduras (muchas de ellas a juego), mesas de piedras, espejos, arañas y cornucopias.

La evidente atracción por la pintura hizo que se anunciaran durante estos años almonedas exclusivas, en las que a veces también había dibujos, estampas y esculturas. La oferta viene a confirmar los lamentos ya citados de Ponz y Jovellanos, pero al mismo tiempo muestra que seguía existiendo un interés en el mercado por adquirir y formar nuevas colecciones, lo que no dejaba de ser la misma práctica de legitimación con la que proyectar la distinción social a través del capital artístico ${ }^{42}$, aunque en esta ocasión la clientela fuera la emergente burguesía y la nueva clase de funcionarios que ocupaban los altos cargos de la carrera administrativa del Estado ${ }^{43}$.

adornar, o servir una casa». También son de enorme interés las voces compuestas: MUEBLES PARTICULARES "Como cama, vestidos, adorno de cuarto o alcoba" o MUEBles PRECisos "como platos, mesa, cama, \&c.", muestra del amplio abanico de objetos que hoy en día no son considerados mobiliario propiamente, pero entonces sí. TeRREROS Y PANDO, Esteban de. Diccionario castellano con las voces de ciencias y artes y sus correspondientes en las tres lenguas francesa, latina e italiana. Madrid: Imprenta Viuda de Ibarra, Hijos y Cía., 1786-1788, 3 vols.

41. Esta sería la principal diferencia entre abordar las almonedas desde la prensa o desde la documentación notarial, de cuyas estrategias y propuestas de investigación se pueden encontrar un buen resumen en GARCíA FERNÁNDEZ, Máximo. "Cultura material, consumo, moda e identidades sociales: la almoneda de bienes». En Cultura material..., op. cit., pp. 235-259.

42. Urquízar Herrera, Antonio y Vigara Zafra, José Antonio. "La nobleza española y Francia en el cambio de sistema artístico, 1700-1850». En SAZATORnIL RuIZ, Luis y JimÉNo, Frédéric (eds.). El arte español entre Roma y París (siglos XVIII y XIX). Intercambios artísticos y circulación de modelos. Madrid: Casa de Velázquez, 2014, pp. 257-274.

43. Ejemplos de almonedas artísticas son: la que se abrió el 24 de julio de 1793 en «la calle Real del Barquillo n. 18: consta de pinturas, estampas y otros enseres del uso de un facultativo y hay un catre de nogal para viajar que puede colgarse», o la de la "calle del Estudio a la Morería, n. 10" donde "se vende una colección de pinturas originales de los mejores autores, algunas miniaturas y dos medios relieves de bronce de la escuela a Michael Angelo; todas de tamaños proporcionados y estará abierto por la mañana de 9 a 12 y por la tarde de 3 a 5" (DM, 24/09/1793). 
Dado que la mayor parte de las almonedas se abrían tras un fallecimiento, no ha sido posible observar diferencias significativas en los artículos descritos en los anuncios según pasaban los años, entre otras razones porque lo normal es que fueran objetos reunidos a lo largo de toda una vida. Como mucho, se puede observar una tendencia a dejar de usar como reclamo en el periódico los muebles aparatosos en favor de otros artículos más menudos como el menaje del hogar, que tal vez podían encontrar mejor salida. Ejemplo de todo ello son los siguientes dos anuncios, publicados al comenzar y terminar la década:

En la calle de San Vicente baja n. 11 entrando por la de Amanuel o el Colegio de Niñas de Monte-Rey, cuarto principal, primer portal a la derecha, se ha abierto una almoneda, y se venden en ella varios espejos de cuerpo entero, sus lunas de Venecia, cornucopias de especial hechura y grandor, arañas de cristal, muebles de gabinete y china para su adorno, con otros diversos, con la mayor equidad mediante su tasación; se hallará abierta todos los días, excepto los de fiesta, desde las 4 de la tarde hasta las 7 de la misma (DM, 15/06/1790).

En la red de san Luis casa n. 41 se ha abierto una almoneda donde se halla de venta, un tocador de plata, cómodas de caoba, diferentes cuadros de pinturas buenas, una escopeta de Madrid, su autor Agustín Ortiz, otra Vizcaína, un juego completo de tapas de hoja de lata para fuentes, trabajado en Inglaterra imitado a plata, 12 calentadores de peltre para platos uno y otro nuevo, diferentes piezas de loza inglesa, lienzos finos, ropa usada blanca y de color ( $D M, 28 / 09 / 1799)$.

Por el contrario, en almonedas procedentes de casas como las de los citados embajadores, que se veían obligados a dejar la corte por haber cesado en sus funciones diplomáticas, es donde se podía encontrar un mayor número de artículos a la moda, o al menos más acordes con la ostentación que debían proyectar los ambientes de representación de las clases altas:

El Excmo. Sr. Embajador de Cerdeña, marchándose con licencia de esta Corte para Italia, avisa que [en] la misma casa se venden muebles, camas, tapices, cristales, relojes con música y sin ella, lienzos, \&c. \&c. Berlinas a la inglesa de última moda, un vis a vis, y muchas otras cosas. En la casa que tiene dicho Excmo. Sr. en el Real Sitio de Aranjuez se venden también muebles, sillas, cortinas de damasco, canapés, armarios, mesas, cristales, porcelana de Francia, \&c. \&c. Se empezará la venta el lunes 10 desde la nueve de la mañana hasta las cinco de la tarde (DM, 08/12/1798).

Como se puede comprobar por los anuncios expuestos hasta el momento, en el mercado existían numerosas opciones de compraventa para adornar la casa y alquilar una vivienda de acuerdo a los criterios del buen gusto y la moda que exigía la nueva sociabilidad, un escenario donde no podía faltar el nutrido y variado grupo de proveedores, comerciantes, artífices y maestros necesarios para satisfacer las demandas decorativas que, como ya dijimos, implicaban indistintamente la práctica de las bellas artes y las manufacturas. Un ejemplo de la nueva valoración que se empezaba a proyectar en torno a la influencia de estas últimas en el fomento de 
la industria nacional y el impulso del comercio fueron las noticias publicadas en la prensa de 1786 sobre la construcción del «coche nuevo de gala de la Serenísima Princesa nuestra Señora", que estaban ejecutando varios artífices españoles y que, por su espectacularidad, se expuso al público en las reales caballerizas para que todo el mundo pudiera contemplarlo y admirar el resultado de su fabricación.

El Diario curioso, económico y comercial del 20 de julio de 1786 se hizo eco de su descripción en un número especial ${ }^{44}$. En la extensa noticia se explicaban las características técnicas del vehículo y sus distintos elementos decorativos, fácilmente reconocibles en cualquier hogar refinado, como podían ser tallas de «delicadas y gustosas grecas", "adornos de primorosa escultura", "cornisas de arquitectura del orden corintio", "bronces dorados»... También destacaban otros adornos como los "bustos en óvalos de los cuatro primeros reyes de España" o los "tableros de primoroso dibujo y gusto, todos charolados a la perfección" e imitando «en su pintura y fondos a un precioso tisú rayado y escarchado de oro". El interior de la caja iba, por su lado, "vestida de terciopelo fino de color de leche, bordado de plata, oro y talcos de varios colores, con las flores de todos los medios de cuadritos de pedrería", siendo "el fleco de la caja por todo alrededor» de oro, etc. La descripción del vehículo resumía, en definitiva, el lujo y la ostentación que pocos años después harían deslumbrar el reinado de Carlos IV y María Luisa, pero casi más importante que eso es la información que se proporcionaba al público sobre la relación de artífices que habían participado en el proyecto bajo las órdenes del maestro de coches Antonio Durán, compuesta por diez especialistas en distintas artes y manufacturas (Diario curioso, 20/07/1786) ${ }^{45}$. Según una crónica posterior, todos ellos recibieron las felicitaciones y el aplauso del soberano y la familia real cuando fueron a ver el coche dos días más tarde, siendo «admitidos a besar la

44. El interés del acontecimiento motivó que la noticia se publicase en otros periódicos como el Memorial Literario (mayo 1786, pp. 122-130), que incluyó en la sección de Artes la «Descripción de un primoroso Coche que han construido varios Artífices Españoles en competencia de los que vienen de fuera del Reino", aclamando el fomento de las artes y la industria promovido por el rey. Con este tema se publicó una pequeña obrita laudatoria con el sugestivo título de Las Artes triunfantes en el coche de la Serenísima Princesa de Asturias (Oviedo: D. Francisco Díaz Pedregal, Impresor del Principado, 1786), que se anunció en la Gaceta de Madrid del 4 de agosto de 1786. Finalmente, en el Diario curioso erudito económico y comercial del 30 noviembre se insertaba el siguiente anuncio: "Las Artes triunfantes en el coche de la Serenísima Princesa de Asturias, canto que en continuación a la obra publicada en la Gaceta de 4 de agosto escribía el conde de Toreno, Alférez mayor de dicho Principado».

45. El listado completo estaba formado por los dos oficiales de coche a las órdenes de Antonio Durán, Juan Antonio García y Fernando Rodríguez; el tallista Pedro Rodríguez de Arellano; el escultor Esteban de Agreda; el pintor, charolista y dorador Joseph Petit; el platero y broncista Fermín Mendiluce; el guarnecedor Dionisio Salinero; el dorador de fuego Rodrigo de Mesa; el guarnicionero Pedro Bello; el bordador Manuel Camino; el cordonero Juan Delgado, y el pasamanero Manuel Sanz de Velasco. Unos días más tarde, el mismo diario insertaba una nota explicando que no se había incluido en la lista anterior a Antonio Vian, plumista de cámara que había «hecho los plumajes chinescos para los penachos de los caballos, y cuyo primor e idea de colores constituyen la parte principal del mérito que tienen en su adorno, atendida la dificultad que hay en teñir las plumas con perfección» (25/07/1786). 
mano a S. M. [quien] volviéndose a los Artistas, les dijo: Me alegro de vuestra aplicación» (Diario curioso, 23/07/1786) ${ }^{46}$.

El ejemplo de la noticia descrita permite insistir en el carácter educativo del periódico, pues, gracias a la detallada descripción ofrecida en sus páginas a los lectores, el público que se acercara a las reales caballerizas sería capaz de reconocer la factura y cualidades de su fábrica, así como distinguir el refinamiento de los acabados y el buen gusto empleado por sus distintos artífices en la decoración. Desde una dimensión económica, proyectos colectivos como el del coche, además de fomentar la industria sin el control de los gremios para atender mejor las necesidades de la nueva sociedad de consumo, promoverían, según el pensamiento de figuras como Jovellanos, el ingenio de los artistas como nuevo motor en el fomento del comercio:

La creación de nuevas artes sólo puede ser efecto de la libertad. El ingenio, a favor de ella y estimulado por el interés, observa, ensaya, inventa, imita, produce nuevas formas, y crea finalmente objetos que, al favor de la novedad, se buscan y recompensan con gusto por el consumidor ${ }^{47}$

Estas ideas y este tipo de trabajo compartido debían parecerse bastante a la actividad destinada a diseñar y concebir el adorno de la casa independientemente de las manufacturas y artes empleadas. En este caso provocó la aparición de un nuevo perfil profesional cuyas funciones reconoceríamos hoy en la figura del diseñador/a de interiores. El término más parecido que podríamos encontrar en el siglo XVIII es el de "adornista", aunque sus cometidos y perfil profesional no parecían estar muy claramente definidos.

Las referencias más tempranas que hemos registrado en relación con la actividad del adornista le vinculan a la práctica de la arquitectura. En 1766 Juan de

46. Tras el encuentro, «S. M. y Príncipes nuestros Señores se retiraron dando pruebas claras de lo satisfechos que habían quedado por el esmero de los Artífices, y éstos luego empezaron a abrazarse unos a otros con particular regocijo, dándose continuas enhorabuenas, las cuales recibían igualmente de todo el concurso, que fue lucido y numeroso". Independientemente de la veracidad del relato, es obvio que se quiso premiar con esta distinción el trabajo de los artistas y convertirlos en ejemplos a emular. Sobre los ámbitos de trabajo de estos profesionales en la ciudad de Madrid, véase NiETo, José A. Artesanos y mercaderes. Una historia social y económica de Madrid (1450-1850). Madrid: Editorial Fundamentos, 2006, caps. 15-19.

47. Todo ello surgía en un momento de extensos debates en torno al control que todavía ejercían los gremios, considerados cada vez más como un freno al progreso: Molas Ribalta, Pere. "La vida cotidiana de los gremios». En ARIAS SAAVEDRA, Inmaculada (ed.). Vida cotidiana en la España de la Ilustración. Granada: Universidad de Granada, 2012, pp. 113-130 (pp. 115 y ss.). Jovellanos continuaba así su exposición: "Las reglas técnicas de la legislación gremial, el ojo envidioso de los demás maestros, y la hambrienta vigilancia de los veedores y sus satélites, amedrentan continuamente el ingenio y lo retraen de estas útiles, pero peligrosas tentativas", algo que hubiera evitado desde sus inicios la libertad de todas las artes. Jovellanos, Melchor Gaspar. "Informe dado a la Junta General de Comercio y Moneda sobre el libre ejercicio de las Artes». En Escritos económicos. Ed. y estudio preliminar de V. Llombart. Madrid: Real Academia de Ciencias Morales y Políticas, 2000 [1785], pp. 431-466 (p. 443 ). 
Villanueva habla de aquellos que actúan como «adornistas de los interiores de nuestras habitaciones» al llamar la atención sobre el error de muchos jóvenes de hacer primar el ornato por encima de la funcionalidad al diseñar un edificio ${ }^{48}$. Por su parte, el aficionado a las artes Diego Antonio Rejón de Silva definía la voz como el «nombre que se da al arquitecto que sobresale en la parte de la decoración y el adorno de los edificios exterior e interiormente " ${ }^{49}$. No es extraño que fueran los arquitectos quienes asumieran esta tarea, sobre todo cuando tenían la oportunidad de diseñar ambientes homogéneos donde se pensaba de manera conjunta desde la arquitectura hasta la decoración y el mobiliario. Sin embargo, no fue menos habitual que dicho servicio lo desempeñaran igualmente los pintores, cuestión de la que se han podido estudiar diferentes ejemplos en el entorno cortesano al servicio del monarca ${ }^{50}$. En palacio, de hecho, llegaron a ser habituales los títulos de adornista asociados al desempeño de distintos oficios en ámbitos como la platería o la ebanistería, aunque habrá que esperar hasta 1789 para ver nombrado al primer "adornista de la Real Casa y Cámara" con el sentido que le estamos dando, cargo que recayó en Juan Bautista Ferroni ${ }^{51}$. El término se recogió finalmente en el Diccionario de la Real Academia en 1803, cuando se le reconocía escuetamente como "pintor de adornos" ${ }^{52}$. El hecho de asociar la idea de adornista con la profesión de pintor debió tener bastante que ver con los cambios en la decoración de interiores que tuvieron lugar, precisamente, en la década de los años noventa, donde estos artistas asumieron un papel prevalente respecto a otros artífices por la moda, cada vez más extendida, de recurrir a la pintura para adornar las salas.

48. Villanueva, Juan de. Colección de diferentes papeles críticos sobre todas las partes de la Arquitectura, remitidos por un profesor de este Arte fuera del Reino, a otro establecido en una de nuestras provincias. Valencia: Benito Monfort, 1766. Villanueva dice hacerse eco de la correspondencia de un profesor francés donde se equiparan las funciones del adornista a las de plateros, cinceladores y arquitectos, por ser posiblemente las figuras que más directamente estaban implicadas en diseñar y producir objetos y adornos.

49. REJón DE Silva, Diego Antonio. Diccionario de las Nobles Artes para Instrucción de los Aficionados, y uso de los Profesores. Segovia: Antonio Espinosa de los Monteros, 1788. Para el autor, la decoración es la "parte de la Arquitectura, que enseña el modo de adornar un edificio según su clase. Llámase también ornatom.

50. Entre ellos el retratista francés Jean Ranc, que asumió algunos proyectos decorativos durante el reinado de Felipe V y, en tiempos de Carlos III, el veneciano Matías Gasparini, que, pese a acompañar al rey desde Nápoles como pintor de cámara, se destacó por sus diseños como adornista. Véanse los trabajos de López CASTÁn, Ángel. «Jean Ranc y la decoración de la Galería de Poniente del Real Alcázar de Madrid en 1734». Artigrama, 2012, 27, pp. 177-194, y "Mattia Gasparini. Trayectoria vital y profesional de un artista veneciano al servicio de Carlos III. Anuario del Departamento de Historia y Teoría del Arte, 2016, 28, pp. 153-170.

51. JunQuera Mato, Juan José. La decoración..., op. cit., pp. 90-91. Sobre la figura de Ferroni, véase CASTÁN LÓPEZ, Ángel. "La ebanistería madrileña y el mueble cortesano del siglo XVIII (II)». Anuario del Departamento de Historia y Teoría del Arte, 2005, 17, pp. 93-114.

52. No sería hasta la edición de 1817 cuando se completa su definición, añadiendo la acepción de «el que hace o pinta los adornos de salas, gabinetes y muebles preciosos. Entre los romanos fue oficio de palacio en tiempo de los emperadores». 
Esta se fue imponiendo progresivamente en detrimento de tapices, colgaduras y papeles pintados.

Cuando acudimos a la prensa, no obstante, el término adornista no se vincula a un oficio en particular, sino que se destaca como una función que podían acometer diversos profesionales. Así, pues, en las escasas veces que encontramos citado el término, se asocia a figuras como el «sujeto hábil en el oficio de guardarropa, o artífice adornista» que sabía, entre otras cosas, "vestir las casas a la francesa, la italiana y portuguesa" (Diario curioso..., 10/11/1786); el "escultor y adornista" que tenía "tienda frente de la inclusa" en la calle de Preciados (DM, 18/09/1797), o el "adornista que pinta salas y gabinetes de gusto con equidad» que vivía en el cuarto tercero interior de la calle del Espejo, número 3 (DM, 21/08/1801) ${ }^{53}$.

Aunque apenas tenemos constancia de menciones a "pintores adornistas" ${ }^{54}$, su cometido sí fue por el contrario frecuentemente descrito. A principios de los años noventa, lo normal era que los pintores de salas y gabinetes tomaran como referencia los diseños de colgaduras y sedas, imitados igualmente en los papeles pintados. En estos términos ofrecía sus servicios el artista que vivía en la calle del Lobo, que pintaba «en las paredes imitando cualquier género de colgadura, así de seda como cotones, muselinas, \&c., con los adornos, frisos y sobrepuertas correspondientes», ocupándose también de pintar "sobre telas de seda, al estilo de Francia, imita[ndo] perfectamente los pekines con perfiles de oro y plata" ( $D M$, 06/04/1788). El "pintor de salas y gabinetes» que vivía en el cuarto principal de la casa número 5 de la calle de la Cabeza también pintaba "cualquier pieza que sea imitada a muselina o colgantes de flores a 4 rs. cada vara y si es sólo con tableros y fajas de colores a 3" (DM, 13/08/1794). En esta misma línea trabajaba el "artífice de pintor el cual pinta salas, gabinetes y techos con diferentes adornos y flores de lo que se estila en el día, todo hecho con primor, imitando el natural» (DM, 09/04/1790). Con esta última observación pretendía equipararse a un artista aunque no tuviera el estatus de profesor de pintura, es decir, el artífice dominaba la mímesis e ilusión que le eran propios al arte de la pintura. Por razones parecidas, era conveniente informar sobre otras habilidades que también eran valoradas,

53. Lo normal es que todos ellos tuvieran experiencia previa en oficios ya asentados, aprovechando la enorme demanda de las nuevas élites para reciclar sus conocimientos y adaptarse a los nuevos tiempos. Un ejemplo temprano pero muy representativo por los casos similares que se encuentran en la prensa sería el de "Don Luis Belache, natural de París, y maestro tapicero", que al margen de mantener su actividad habitual como creador de "colgaduras de camas a lo moderno" o el guarnecido de "sillerías a la francesa e inglesa", había comenzado a colgar "salas y gabinetes, así de seda como de papel con toda equidad y brevedad" (Diario curioso..., 06/08/1786). Respecto al oficio de tapicero, véase una aproximación en BENITO, Pilar. «El Oficio de Tapicería del Palacio Real de Madrid». Arbor, 2003, CLXIX/665, pp. 193-219.

54. Uno de los escasos anuncios que hemos encontrado es el que sigue: «En la calle del Desengaño frente a la casa del Pasadizo, fábrica de sillas de paja finas, darán razón de un pintor adornista, que pinta salas y gabinetes, anaquelerías de lonjas al óleo, de todas clases con la mayor equidad” (DM, 23/04/1797). 
como las que explica tener el sujeto del que daban razón «en la barbería que está frente a la yesería de la calle de la Fe junto a San Lorenzo»:

Pinta según las ordenes de arquitectura y de coloridos delicados con una composición que permanece con mucho valor, advirtiendo que en las casas que se fabrican pueden los dueños ahorrarse el blanqueo de las piezas que gusten ser pintadas y solamente mandar enlucir el yeso negro, lo cual es en beneficio de la pintura lo que hará con toda la equidad ( $D M, 15 / 02 / 1794)$.

El conocimiento de la arquitectura y el dominio del colorido serían dos requisitos clave para determinar la calidad de un buen artista y, en definitiva, la de otros tantos sujetos que empezaban a desempeñar el cometido de "adornistas" como los doradores, cuyo título en los anuncios casi siempre se acompañaba del de pintor ${ }^{55}$.

En lo que se refiere a la arquitectura, esta en combinación con la formación en el dibujo permitía a los artífices los conocimientos necesarios para diseñar cualquier tipo de objeto siguiendo las reglas del arte. Un recurso básico para su formación lo constituyeron las cartillas para aprender a dibujar, algunas de ellas explícitamente se anunciaban como obras que comprendían "las tres nobles artes, y son muy útiles para los adornistas, tallistas, plateros y doradores» (Diario curioso..., 31/01/1787). De los diversos modelos que circularon, el más conocido fue el de las cartillas que componían el "método sucinto y compendioso de 5 simetrías apropiadas a las 5 órdenes de arquitectura, adornada con otras reglas útiles» (DM, 26/10/1790), es decir, el Método de Matías de Irala publicado en 1739; todavía en las décadas finales del siglo seguía teniendo una enorme acogida entre quienes se formaban como artistas.

No obstante, el conocimiento de los órdenes y de las normas básicas de la ornamentación no eran suficientes si no se era capaz de tener un conocimiento crítico de la arquitectura en todas sus dimensiones, el cual solo se podía adquirir mediante la lectura y comprensión de sus tratados. La prensa de estos años anunció la publicación de algunos títulos clásicos como los de Vitruvio, Alberti o Vignola, y otros más modernos procedentes de autores franceses como Mr. Peyre, o de los propios españoles, como los ya citados de Villanueva o Bails ${ }^{56}$. Como se

55. Suponemos que la mayoría de ellos no dominaban el arte de la pintura, pero podían acometer sin dificultad tareas como el pintado de puertas, camas y maderas de toda clase, el charolado de coches, lacados de muebles, etc. Sirva este anuncio como ejemplo de este tipo de servicios: "En la calle de la Magdalena, inmediato a la fuente de Relatores, frente a la casa del Sr. Marqués de Perales, vive un dorador que dora y pinta todo género de adornos para salas y gabinetes, imitando a damasco en las paredes, como también frisos, camas, coches, hace jaspes imitados a piedra y todo género de maderas veteadas, todo con la mayor equidad" (DM, 09/04/1793).

56. Sobre la recepción y lectura de la tratadística artística en la segunda mitad del siglo XVIII, véase Crespo Delgado, Daniel. "Lectura y lectores...", op. cit., pp. 31-60. Por lo general estas obras iban dirigidas a los profesionales y aficionados, aunque su elevado precio motivaba que su consulta se realizara en las bibliotecas de instituciones como las reales academias o escuelas destinadas a la enseñanza del dibujo. Al respecto de las ventas de estas obras en la Academia, el conserje encargado 
indicaba en el anuncio de uno de ellos, la utilidad de estos tratados era que en sus páginas se podían encontrar «todos los principios y reglas del arte que pertenecen no sólo a la fábrica de los edificios, sino también al buen gusto de su adorno y comodidad de las habitaciones ${ }^{57}$. También contribuían a formar un conocimiento crítico y razonado de la Antigüedad, aportando útiles lecciones para asimilar, conforme al buen gusto, su transferencia al ámbito decorativo, lo cual era a su vez símbolo de modernidad. El tratado de Vitruvio, por ejemplo, se anunció en el Memorial Literario (septiembre 1787, pp. 46-50), celebrando así la magnitud de la empresa:

Grande ha sido el empeño de todas las Naciones cultas de Europa en traducir y comentar cada una en su respectivo idioma la presente obra de Vitruvio, la más excelente y completa de cuantas se han escrito hasta ahora en materia de Arquitectura, así por la belleza de sus conocimientos arquitectónicos, como por contener noticias de antigüedades y monumentos recónditos, dignos de la curiosidad de los Eruditos y Anticuarios.

Traducido y comentado por José Ortiz y Sanz, en el tratado se conectaban las ideas críticas del autor romano con la asimilación contemporánea del pasado. Por ejemplo, cuando Vitruvio se hacía eco de las múltiples monstruosidades que habían llegado a diseñar muchos pintores de su tiempo en la decoración de las casas romanas, el editor de la traducción española añadía en nota que el problema se estaba provocando nuevamente por no saber discernir los artistas el buen gusto de la Antigüedad, de modo que "los pintores y adornistas modernos, muy lejos de corregir semejantes impropiedades, las propagan prodigiosamente por mil modos ${ }^{58}$.

En lo que respecta al color, no hay que olvidar que la sociedad del siglo XVIII se interesó enormemente por esta cuestión, pues fue un aspecto clave en las artes y las manufacturas, aunque su análisis se haya centrado normalmente en los estudios sobre textiles ${ }^{59}$. En el tema que nos ocupa, los colores condicionaron de

de las mismas en 1808, Francisco Durán, explicaba la poca salida que tenían porque «Sólo las compran los conocedores de las nobles Artes, los cuales, por desgracia, son tan pocos como Vd. Sabe» (p. 35).

57. AlBerTi, León Baptista. Los diez libros de Arquitectura. Madrid: José Franganillo, 1797, 3 vols. Se trataba de una "obra útil a los profesores y aficionados" por "las muchas noticias históricas con que está enriquecida” (DM, 18/09/1798),

58. En consecuencia, se debía evitar el exceso que podía provocar imitar la Antigüedad sin comprenderla, como sucedía cuando estos motivos eran efecto de la moda y la ignorancia, pues "para conseguir la aprobación del vulgo, basta producir cosa nueva, o por nuevo camino; sin pararse en la verosimilitud e impropiedad: de manera que en agregar semejantes desconciertos nos diferenciamos poco de los chinos". VITRuVIo. Los diez libros de architectura, traducidos del latín y comentados por Don José Ortiz y Sanz. Madrid: Imprenta Real, 1787, p. 179. Sobre el modo de difundir los hallazgos de Pompeya y Herculano a través de las lujosas empresas del grabado y su impacto en las artes decorativas de finales de siglo, véase VEGA, Jesusa. "Interrelaciones entre técnica y realidad en el arte de la corte borbónica: la Antichità de Ercolano Esposte». Ars Longa, 2016, 25, pp. 167-179.

59. La recuperación de los espacios domésticos del periodo desde esta perspectiva ha sido estudiada por ABAD-ZARDOYA, Carmen. "Ratas, cenizas y perlas. El vocabulario del color en los interiores 
modo decisivo la percepción del espacio, máxime si tenemos en cuenta que la decoración implicaba en buena medida revestir diversas superficies como paredes, suelos y muebles. Es decir, se trataba de algo que afectaba por igual a telas, papeles o pinturas, y sus connotaciones implicaban también al resto del mobiliario ${ }^{60}$. El color, en definitiva, generaba una clara interdependencia entre distintos géneros de productos, técnicas y adornos, afectando por igual a compradores y vendedores. En el primer caso, puede servir de ejemplo la persona que llegó a insertar un anuncio en el periódico para encontrar un conjunto que pudiera adaptarse a la decoración de su casa, buscaba "12 cortinas de damasco de seda, 8 encarnadas y 4 de color de caña, o el damasco de colgadura equivalente y servible para igual número de cortinas» (DM, 09/08/1790). En el caso de los vendedores, un testimonio elocuente es la interesante visión comercial de Juan Bautista Giroud de Villette, primer director de la Real Fábrica de Papeles Pintados, quien informaba que si a algún cliente no le agradaba «el pintado de sus dibujos, podrá sin que para ello se le suba el precio, mandarlos hacer de los colores de su gusto, lo que se ejecutará siempre en ocho días de término" (Gaceta de Madrid, 03/03/1789).

La publicación de anuncios sobre este establecimiento en la prensa es igualmente interesante porque, tanto en formato como en contenidos, seguía las tempranas políticas publicitarias de los fabricantes de Francia, de donde procedían sus dueños ${ }^{61}$. En el anuncio que acabamos de citar, se informaba al público sobre la variedad de productos disponibles en su almacén, todos de buen gusto y a la moda, así como los precios y ofertas, las opciones de venta al por mayor y menor, y otros servicios ofrecidos para satisfacer a los compradores:

Está surtido su almacén de crecido número de piezas, y es muchísima la variedad en los dibujos del gusto más especial y moderno, de suerte que esta nueva fábrica española puede en el día competir de primores con las extranjeras más adelantadas. Los precios van equitativamente arreglados a la calidad del papel y al género de los dibujos y colores, en tal conformidad que cualquiera clase de personas los

del siglo XVIII". Res Mobilis, 2016, 5/5, pp. 22-46 (p. 23).

60. Esto último explica la constante oferta de pintores-doradores que ofrecían sus servicios para trabajar en toda clase de muebles y maderas, como Manuel Méndez, que vivía en el cuarto interior de la casa de Aytona de la calle de la Magdalena. A principios de la década publicó numerosos anuncios describiendo sus servicios y precios, entre los que se encontraban el pintado de camas imperiales, cabeceras y juegos de coche, puertas, ventanas y balcones al óleo o de color de porcelana; techos y frisos imitados en damasco, maderas y piedras imitando mármoles "y otras muchas frioleras de su facultad que se ofrece a hacer con la mayor equidad» $(D M, 20 / 06 / 1792)$. Para los suelos, era también frecuente buscar tonalidades que fueran bien con el resto del adorno, como hacía saber "un sujeto de nación flamenca que sabe dar el barniz en los suelos con toda perfección, del color que quieran", al que se podía contratar en la sombrerería de la calle de Santiago, número 5 ( $D M, 29 / 08 / 1796)$.

61. Rose-DE VIEJO, Isadora. La Real Fábrica de Papeles Pintados de Madrid (1786-1836). Madrid: Cátedra, 2015, p. 38. El establecimiento fue promovido con el apoyo de la corona como parte de su política para fomentar la creación de fábricas nacionales capaces de competir con los productos extranjeros. 
encuentre proporcionados a sus facultades, sin menoscabo del lucimiento propio de este género de adorno ${ }^{62}$.

De acuerdo a las técnicas comerciales modernas, la fábrica disponía además de un espacio destinado a comprobar el efecto de los papeles ya montados sobre la pared, invitando así a los potenciales clientes a ver el efecto de los mismos en una sala, como sucedía con «el dibujo especial de arquitectura con columnas, pilastras, cornisas y estatuas, representando el friso un hermosísimo jardín con flores perfectamente imitadas, y en la parte superior una imitación de damascos bordados de oro o plata con sus correspondientes borlas» (DM, 12/06/1789), o los "nuevos dibujos arabescos, y de arquitectura de diferentes decoraciones, y en el día se hace de último gusto, variando también los colores a voluntad de los compradores» (DM, 02/04/1791).

La introducción del papel pintado supuso sin duda alguna disminuir los elevados costes que implicaba vestir de sedas y damascos las paredes, lo que no significaba que la alta aristocracia e incluso la burguesía adinerada no siguiera recurriendo a ellas en sus piezas de representación. Tampoco implicaba que el resto de hogares pudiera permitirse el uso de los papeles en todas las habitaciones. Una opinión ilustrativa de los múltiples clientes que podían optar por este producto en función de su poder adquisitivo la expresa Eugenio Larruga pocos años antes de abrirse la fábrica de Giroud de Villette:

El gusto, lujo o capricho de las gentes, ha venido a introducir de tal suerte el uso de estos papeles en el adorno interior de las casas, que aun las gentes de poquísimas conveniencias, no dejan de tener algunos frisos de ellos. En las casas de mayor suposición, se usan generalmente para los primeros recibimientos, cuartos de comer, y algunas otras piezas que no son del mayor respeto; de suerte, que por esta moda casi generalmente, no sólo en la Corte, y Sitios Reales, sino también en las demás Ciudades, y aun en los lugares, es inmenso el consumo de estos géneros ${ }^{63}$.

El método empleado en la decoración de las paredes dependía, pues, de otros factores a considerar como el decoro que debía guardarse en determinadas dependencias ${ }^{64}$, de ahí que siguieran anunciándose durante estos años numerosas colgaduras y tapicerías, de las que ya apenas se informaba sobre sus motivos

62. El primer anuncio que hemos registrado de la Real Fábrica en el Diario de Madrid se insertó el 28 de mayo de 1789, aunque por los índices del propio periódico sabemos que unos días antes se insertó otro anuncio como hoja suelta y sin encuadernar, cuyo contenido era posiblemente similar al de la Gaceta.

63. LaRruga, Eugenio. Memorias políticas y económicas sobre los frutos, comercio, fábricas y minas de España. Madrid: Antonio de Espinosa, 1788, tomo III, pp. 117-118.

64. Entenderíamos aquí la idea de decoro como el conjunto de reglas que determinaban la relación entre los usos, ubicaciones, destino e, incluso, orientación de las habitaciones de una vivienda o palacio con sus elementos decorativos y la naturaleza material o artística de los mismos: Herrero CARretero, Concha y Glendinning, Nigel. «El estado de la cuestión: cartones y tapices». En Congreso 
decorativos o del tema de sus historias, sino sobre las dimensiones de los paños y el coste que podía suponer para cubrir la superficie en cuestión. Sirvan de ejemplo los «cuatro juegos de tapices de 5 1/2 anas de caída y 7 de corrida bien tratados de varias historias y varias pinturas» de los que daba razón un maestro de coches de la calle Amor de Dios (DM, 04/07/1792) o la "colgadura de 24 paños, de más de media vara, con cenefa, fondo raso de color de caña, bordada de cordoncillo, con sobrepuestos de terciopelo de varios colores, en buen dibujo", que estaba a la venta en la tienda de fideos y puesto del cotillero de "la calle Toledo, frente a las monjas de la Concepción Francisca» $(D M, 27 / 11 / 1794)^{65}$.

Algo similar sucedía con los pintores de salas y gabinetes, quienes establecían los precios en función de la superficie a pintar y el tipo de adorno solicitado. El abanico de importes estaba bastante delimitado: pintar las paredes de liso venía a costar -según las ofertas anunciadas en el periódico por estos artífices- entre 2 y 3 reales la vara, mientras que la introducción de adornos podía llegar a doblar el precio en algunos casos. Así pues, en la calle de Carretas vivía a finales de la década de los ochenta «un artista pintor que pinta las paredes, imitando todo género de colgaduras de seda, filoseda, damasco de la china y cotones [...] a 4 rs. la vara en cuadro", costando de 2 a 4 reales más al solicitar "puntos de arquitectura u otras cosas» (Diario curioso, 07/04/1787); a principios de los noventa se podía contratar a otro que paraba en la calle de San Gregorio que pintaba "todo género de adornos, como también salas y gabinetes con todo primor, frisos de todas calidades, advirtiendo que la vara de pintado de liso es a 3 rs. y con adornos de buen gusto a 4 1/2» (DM, 01/07/1793).

Aquellos sujetos que participaban en las redes de sociabilidad de élite de la corte podían, finalmente, recurrir a otro tipo de artistas que, por su reconocimiento o por la especialidad que ejercían, no anunciarían sus servicios en la prensa ya que disponían de una clientela que les requería por su celebridad y distinción social. Un buen ejemplo son los hermanos Tadey, pintores de escenografía procedentes de Milán, encargados de componer los decorados del Teatro del Príncipe y el de los Caños, en cuya actividad gozaron de enorme éxito desde finales de los años ochenta por los efectos ilusionistas logrados en sus composiciones ${ }^{66}$. Prueba de

Internacional Goya 250 años después. 1746-1996. Marbella: Museo del Grabado Español Contemporáneo, 1996 , pp. 23-37 (p. 28).

65. En lo que se refiere a tapicerías historiadas, su uso apenas debió ser frecuente más allá de las casas de la vieja aristocracia, por lo que se trataba de productos con difícil salida en el mercado. Muchos de ellos aparecen anunciados a lo largo de varios años, como "la tapicería de gusto y bien tratada historia de Alejandro [que] se compone de 16 piezas de 393 varas y se dará con mucha equidad” en la casa número 28, cuarto segundo, de la calle de los Negros (DM, 26/10/1792). Dos años más tarde se volvía a anunciar informando que el coste original había sido de 60.000 reales, y aunque su tasación era de 11.790 , se vendía por 5.895 ( $D M, 18 / 11 / 1794)$, precio mantenido un año más tarde (DM, 14/12/1795).

66. ARIAS DE Cossío, Ana María. Dos siglos de escenografía en Madrid. Madrid: Mondadori, 1991, pp. $45-49$ 
su reconocimiento público es que sus nombres solían aparecer en los avisos de aquellas obras teatrales, óperas y bailes en las que participaban con nuevas escenografías $^{67}$, por lo que no extraña que también fueran utilizados como reclamo para el traspaso del cuarto segundo de una casa nueva de la calle San Ildefonso, que constaba de "9 piezas útiles, un recibimiento y una buhardilla, amueblado de moda y pintado por los célebres hermanos D. Antonio y D. Ángel Thadeis; quien quisiere entrar en dicho traspaso acudirá a la misma casa para verlo y tratar con el mismo inquilino" $(D M, 24 / 10 / 1799)^{68}$.

Si el conocimiento de cuestiones como las de los pintores escenógrafos en el siglo XVIII sigue siendo una asignatura pendiente, es fácil imaginar lo poco que sabemos en nuestros días de los trabajos que pudieron desarrollar fuera de su actividad principal, así como todas aquellas transferencias artísticas que se produjeron como resultado de las relaciones sociales, los encargos particulares de amistades, compromisos familiares, etc. Un último ejemplo que resulta ilustrativo de cómo incluso la prensa apenas recoge unos breves fragmentos momentáneos y casi siempre anónimos de lo cotidiano son las incursiones que pintores como Goya, que ha eclipsado las biografías de muchos artistas coetáneos, tuvieron en esta actividad, como los majos que pintó a principios de la década de los años ochenta para la chimenea de su amigo Martín Zapater -los cuales causaron bastante asombro según nos cuenta en su correspondencia- o las presiones que recibió de este último para que ideara un adorno integral en la casa de Juan Martín de Goicoechea, un encargo que terminó aceptando finalmente pese a sus reservas iniciales, pero del que no ha quedado registro, como la mayor parte de los adornos de los que hemos dado noticia a través de las páginas de la prensa ${ }^{69}$.

67. «En el Coliseo del Príncipe, por la Compañía del Sr. Luis Navarro, se representa la comedia intitulada: La Verdad en el Engaño, nueva, de Teatro, con 7 decoraciones nuevas, pintadas por los Hermanos Tadey, y entre ellas se ha copiado una que representa un Atrio del original que hizo el célebre D. Alejandro Velázquez, para conservar la memoria de un Profesor de tanto mérito» (DM, 01/12/1795).

68. La casa adornada por los Tadey se volvía a anunciar unos días más tarde, añadiendo que "a la misma casa a tratar con el inquilino también hay de venta en el mismo cuarto otros muebles, ropas y libros de varias literaturas y todo se venderá junto o separado» (DM, 02/11/1799).

69. Véase el desarrollo de este episodio en VEGA, Jesusa. "Goya y la vida moderna a través de su correspondencia». En Martínez Millán, José; Camarero Bullón, Concepción y luzzi Traficante, Marcelo (coords.). La corte de los Borbones..., op. cit., vol. 3, p. 1990. 